\title{
Effect of Electrochemical Stimulation of the Amygdala on Induction of Ovulation in Different Types of Persistent Estrous Rats and Castrated Male Rats with an Ovarian Transplant*
}

\author{
YASUMASA ARAI \\ Department of Anatomy, Juntendo University School of \\ Medicine, Hongo, Tokyo
}

\begin{abstract}
Synopsis
The amygdaloid nuclear complex was stimulated electrochemically in two different types of persistent estrous rats and in castrated male rats bearing an ovarian transplant. In persistent estrous rats induced by continuous illumination, ovulation could be obtained by the electrochemical (EC) stimulation of the medial part of the amygdala ( 8 out of 12 rats), but the EC stimulation of other areas in the amygdala was ineffective in inducing ovulation. In androgenized rats (treated with $1 \mathrm{mg}$ testosterone propionate at 5 days of age), the EC stimulation could not induce ovulation in any of these rats. In addition, ovulation and corpus luteum formation did not occur in ovarian transplants following the EC stimulation of the amygdala in castrated male rats. These results suggest that the amygdaloid influence on the hypothalamic-pituitary gonadotrophic function in lightinduced persistent estrous rats may differ in nature from those in androgenized rats and male rats.
\end{abstract}

Evidence from studies on the effects of lesioning and stimulation of the amygdala suggests that afferent inputs to the hypothalamus from the amygdala are involved in modulating the pituitary gonadotrophic function. Bilateral lesions of the medial amygdaloid complex or stria terminalis activated precocious sexual development in immature female rats (Elwers and Critchlow, 1960); conversely, stimulation of the same part of the amygdala delayed puberty (Bar-Sela and Critchlow, 1966). These findings have led to an assumption that the amygdala exerts a

Received for publication April 9, 1971.

* A report of this study was presented at a symposium on Regulatory Activity of Hormonal Secretion by Hypothalamic-Pituitary-Gonadal System, at 18th General Meeting of the Eastern Branch of Japan Endocrinological Society (Oct. 31-Nov. 1, 1970) in Tokyo. This study was supported by a grant from the Ministry of Education of Japan. tonic inhibitory influence on gonadotrophin secretion, at least prepuberally. However, since the earlier stimulation experiments of Koikegami et al. (1954) in rabbits and of Bunn and Everett (1957) in rats, the possibility that the influence of the amygdala may be stimulatory has been suggested by several investigators (Sawyer, 1959; Yamada and Greer, 1960; Hayward et al., 1964; Velascoe and Taleisnik, 1969; Kawakami et al., 1970).

In the present study, as one step in elucidating the nature of the amygdaloid influence on the hypothalamic pituitary gonadotrophic function, the effect of electrochemical stimulation (see Everett and Radford, 1961; Terasawa and Sawyer, 1969) of the amygdala on the ovulatory response was investigated in two different types of persistent estrous rats and castrated male rats bearing an ovarian transplant. 


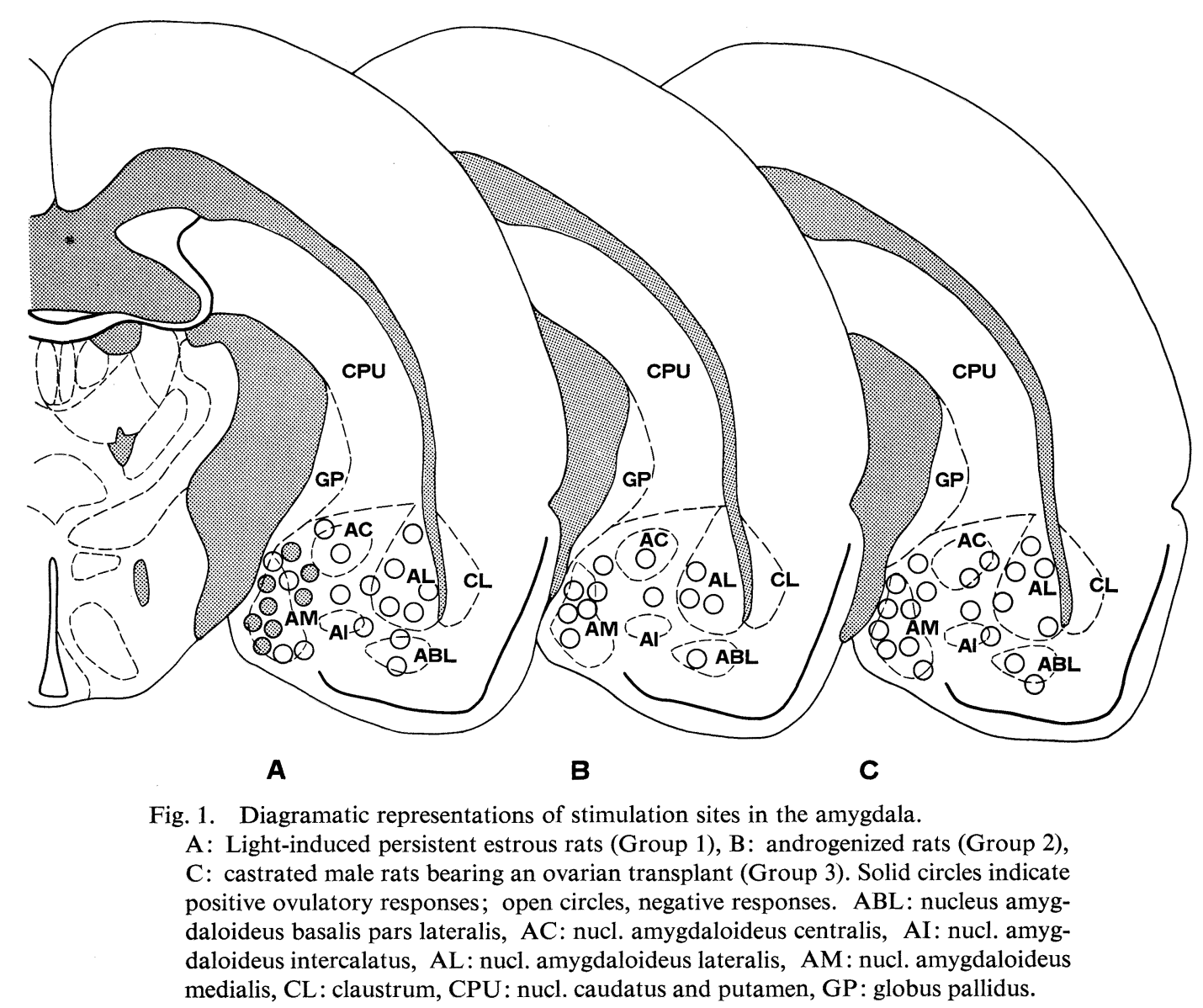

Fig. 1. Diagramatic representations of stimulation sites in the amygdala

A: Light-induced persistent estrous rats (Group 1), B: androgenized rats (Group 2), C: castrated male rats bearing an ovarian transplant (Group 3). Solid circles indicate positive ovulatory responses; open circles, negative responses. ABL: nucleus amygdaloideus basalis pars lateralis, AC: nucl. amygdaloideus centralis, AI: nucl. amygmedialis, CL: claustrum, CPU: nucl. caudatus and putamen, GP: globus pallidus.

\section{Materials and Methods}

Male and female rats of the Wistar strain maintained under controlled temperature and lighting were used in the present experiments. For the production of persistent estrous rats by the continuous exposure to light, the animals were kept under continuous illumination with fluorescent light for 2 months or more and vaginal smears were examined daily to confirm oneset of persistent vaginal estrus. Only those animals which showed persistent vaginal estrus at least for 3 weeks were incorporated in Group 1. Another type of persistent estrous rats, androgenized rats, were produced by a single injection of $1 \mathrm{mg}$ testosterone propionate in $0.05 \mathrm{cc}$ sesame oil at 5 days of age (Group 2). Vaginal smears were examined daily until the amygdaloid stimulation at about 100 days of age. In Group 3, male rats (about 70 days old) were castrated and simultaneously received an ovarian graft from litter mates subcutaneously. The stimulation was performed 4-6 weeks after transplantation.

For electrochemical (EC) stimulation, anodal current of $200 \mu \mathrm{A}$ (DC) was applied for $20 \mathrm{sec}$ under thiopental anesthesia $(50 \mathrm{mg} / \mathrm{kg}$, ip) through the monopolar stainless steel electrode stereotaxically introduced to the amygdaloid complex unilaterally. Results were evaluated 2 or 3 days after the EC stimulation by the presence of new corpora lutea, which was confirmed by the histologic examination. Each brain was removed and the precise localization of the stimulation sites was verified histologically.

\section{Results and Discussion}

The results are summarized in Figure 1A-C. Rats kept under continuous illumination (Group 1) showed persistent vaginal cornifi- 
cation. At laparotomy before the stimulation, their ovaries contained only vesicular follicles. There was no sign of a recent ovulation, although old luteal tissue was found in limited number of rats. In rats of Group 2, persistent vaginal cornification and polycystic ovaries were characteristic. In 8 out of 12 persistent estrous rats induced by continuous illumination (Group 1), ovulation could be obtained by the EC stimulation of the medial amygdaloid nucleus and its surroundings. Similar placement of the electrode without stimulation (3 rats) was ineffective. The EC stimulation of the lateral parts of amygdala failed to induce ovulation (12 rats). These results confirmed the previous findings of Bunn and Everett (1957) and Velascoe and Taleisnik (1969) in light-induced persistent estrous rats and also of Kawakami et al. (1970) in normal female rats. Apparently in this type of persistent estrous rats the release of LH by the anterior pituitary appeared to be activated by the stimulation of the neurons of the medial amygdaloid complex. This part of the amygdala has been suggested to be capable somehow of evoking the hypothalamus to trigger LH release (Koikegami et al., 1954; Sawyer, 1959; Hayward et al., 1964; Kawakami et al., 1966; Velascoe and Taleisnik, 1969; Kawakami et al., 1970).

In contrast, the EC stimulation of the amygdala could not induce ovulation in any androgenized rats (12 rats, Group 2) even if the stimulation was applied to the medial amygdaloid nucleus (5 rats)*, the stimulation of the comparable site being successful in light-induced persistent estrous rats (Group 1). In addition, ovulation and corpus luteum. formation did not occur in ovarian transplants following the EC stimulation of the amygdala in castrated male rats (20 rats, Group 3). Recently Velascoe and Taleisnik (1969) sug-

\footnotetext{
* During preparation of this manuscript Terasawa (1971) published data which demonstrate that the EC stimulation of the amygdala is ineffective in inducing ovulation in androgenized female rats.
}

gested the existence of functional sex difference in the amygdala, based on the results that high levels of plasma LH following the EC stimulation of the medial amygdaloid nucleus and subsequent ovulation were observed in female rats, but no increase in plasma $\mathrm{LH}$ after the stimulation in the males. The failure of the EC stimulation of the amygdala to induce luteinization in ovarian grafts in castrated male rats in the present experiments is consistent with the idea of Velascoe and Taleisnik (1969). The apparent difference in responsivity of the amygdala to the EC stimulation between light-induced persistent estrous rats (Group 1) and androgenized rats (Group 2) may reflect difference in the functional role or capacity of the amygdala in modulating the hypothalamic sex centers, because the EC stimulation of the preopticanterior hypothalamic area did induce ovulation equally in both types of persistent estrous rats and also in castrated male rats with an ovarian graft (Quinn, 1966; Moll and Zeilmaker, 1966; Terasawa et al., 1969; Arai and Masuda, 1970; Everett et al., 1970; Arai, 1971 and unpublished data).

It has been suggested that exposure to endogenous or exogenous gonadal steroids during neonatal life causes a permanent masculinization of the hypothalamic neuroendocrine mechanisms (see Barraclough, 1967; Arai, 1968; Gorski, 1971). Since the amygdala of male and androgenized female rats was highly resistant to the EC stimulation in the present experiments, some impairment of the amygdaloid neural substrates could be assumed. The refractoriness of the amygdala to the EC stimulation in these rats may represent a characteristic masculine feature of the amygdala, and also may suggest that neonatal influences of androgen are focussed on the amygdala as well as on the hypothalamus. In this connection, it is of special interest to note the recent findings of Clayton et al. (1970) that the amygdala and anterior hypothalamus may represent primary sites for the action of androgen given neonatally because of marked 
difference in RNA metabolism in response to androgen from other parts of the brain.

Eleftheriou and his associates (1967) are of the opinion that the lateral amygdaloid complex is exerting a tonic inhibitory influence on the pituitary gonadotrophic activity in deermice, because of continuous high level of plasma LH following lesioning the lateral complex of the amygdala. Similar high level of plasma LH was also detected after bilateral lesions of the cortical amygdaloid nucleus in the ovariectomized rats (Lawton and Sawyer, 1970). In the present experiments, the result supporting that the influence of the lateral or cortical amygdaloid nucleus is inhibitory could not be obtained, but it should be kept in mind that experimental conditions were different between earlier investigations and our own. Further studies are necessary to solve these problems.

\section{References}

Arai, Y. (1968). Juntendo Med. J. 14, 145 (In Japanese).

Arai, Y. (1971). Folia Endocrinol. Japon. 46, 30 (In Japanese).

Arai, Y. and S. Masuda (1970). Endocrinol. Japon. 17, 237.

Barraclough, C. A. Neuroendocrinology II (edited by L. Martini and W. F. Ganong). Academic Press, N. Y., p. 61 (1967).

Bar-Sela, M. E. and V. Critchlow (1966). Am. J. Physiol. 211, 1103.

Bunn, J. P. and J. W. Everett (1957). Proc. Soc. Exptl. Biol. Med. 96, 369.

Clayton, R. B., J. Kogura and H. C. Kraemer (1970). Nature 226, 810.

Eleftheriou, B. E. and A. J. Zolovick (1967). J. Reprod. Fert. 14, 33.
Eleftheriou, B. E., A. J. Zolovick and R. L. Norman (1967). J. Endocrinol. 38, 469.

Elwers, M. and V. Critchlow (1960). Am. J. Physiol. 198, 381.

Everett, J. W. and H. H. Radford (1961). Proc. Soc. Exptl. Biol. Med. 108, 604.

Everett, J. W., J. W. Holsinger, G. H. Zeilmaker, W. C. Redmond and D. L. Quinn (1970). Neuroendocrinology 6, 65.

Gorski, R. A. Frontiers in Neuroendocrinology 1971 (edited by W. F. Ganong and L. Martini) Oxford Univ. Press, London (1971). in press.

Hayward, J. N., J. Hilliard and C. H. Sawyer (1964). Endocrinology 74, 108.

Kawakami, M., K. Seto and K. Yoshida (1966). Jap. J. Physiol. 16, 254.

Kawakami, M., E. Terasawa and T. Ibuki (1970). Neuroendocrinology 6, 30.

Koikegami, H., T. Yamada and K. Usui (1954). Folia Psychiat. Neurol. Japon. 8, 7.

Lawton, I. E. and C. H. Sawyer (1970). Am. J. Physiol. 218, 622.

Moll, J. and G. H. Zeilmaker (1966). Acta Endocrinol. 51, 281.

Quinn, D. L. (1966). Nature 209, 891.

Sawyer, C. H. Recent Progress in the Endocrinology of Reproduction (edited by C. W. Lloyd) Academic Press, N. Y., p. 1 (1959).

Terasawa, E. (1971). Folia Endocrinol. Japon. 46, 1057 (In Japanese).

Terasawa, E. and C. H. Sawyer (1969). Endocrinology 84, 918.

Terasawa, E., M. Kawakami and C. H. Sawyer (1969). Proc. Soc. Exptl. Biol. Med. 132, 497.

Velascoe, M. E. and S. Taleisnik (1969). Endocrinology 84, 132.

Yamada, T. and M. A. Greer (1960). Ibid. 66, 565. 